\title{
Experiential Learning from a Constructivist Perspective: Reconceptualizing the Kolbian Cycle
}

\author{
Farooq Mughal (Corresponding author) \\ Department of Management Sciences, \\ COMSATS Institute of Information Technology (CIIT) \\ Park Road, Chak Shehzad, Islamabad - 44000 Pakistan \\ Tel: 0092-336-5232053 E-mail: farooq_mughal@comsats.edu.pk
}

\author{
Aneesa Zafar \\ Department of Management Sciences, \\ COMSATS Institute of Information Technology (CIIT) \\ Park Road, Chak Shehzad, Islamabad - 44000 Pakistan \\ Tel: 0092-333-5625633Ｅ-mail: aneesa_zafar@comsats.edu.pk
}

Accepted: November 6, 2011 Published: December 13, 2011

Doi:10.5296/ijld.v1i2.1179 URL: http://dx.doi.org/10.5296/ijld.v1i2.1179

\begin{abstract}
The aim of this paper is to critically analyze Kolb's theoretical model on experiential learning from a constructivist perspective by relating it to more contemporary practices in the field of experiential education. It has been observed that the experiential learning phenomenon has been overwhelmed by individualistic views and overly deterministic intents of reconceptualization. In particular, this paper investigates the deficiencies in Kolb's experiential learning cycle by comparing it with alternate conceptions to learning proposed by Fenwick (2001). The discussion further develops a theoretical critique based on assumptions compiled after a theoretical discourse of the literature enlisting factors which question the effectiveness of the learning cycle. Lastly, the authors propose modifications in the concept of experiential learning by identifying the environmental and structural constraints which may affect the effectiveness of the experiential learning process.
\end{abstract}

Keywords: experiential learning, constructivism, Kolb's experiential learning cycle 


\section{Introduction}

Experiential learning has always been mistakenly used interchangeably with experiential education. Without going in depth the authors try distinguishing briefly the difference between experiential education and experiential learning earlier on to avoid any misconception throughout the reconceptualization. Itin (1999) describes experiential education as, 'a process that occurs between a teacher and a student that infuses direct experience with the learning environment and content'. It is a methodology inspired by experience to engage learners to reflect on their actions to gain knowledge and develop skills and abilities of students (Dirkx \& Lavin 1991). On the other hand, experiential learning refers to, 'making meaning from direct experience'. Experiential learning plays a supporting role in experiential education which facilitates the process of knowledge creation, sense-making and knowledge transfer in teaching, training and development. Since its conception by John Dewey in the mid 1930's, experiential education has been used in multiple disciplines including sociology, anthropology, science and research due to its interdisciplinary nature (Carver, 1996). However, David Kolb's (1978) theory of experiential learning has greatly contributed to the expanding philosophy of experiential education.

Contributing further to the discussion of experiential learning, Brookfield (1983) indicates that experiential learning has been used in two contrasting ways. The first view focuses on learning that takes place in which students are encouraged to 'acquire and apply knowledge, skills and feelings in an immediate and relevant setting' (Borzak, 1981: p.9). In this type of learning academics tend to create an environment with which students' encounter directly to interpret a phenomena rather than thinking about it - facilitated by an institution (Brookfield, 1983). The second view corresponds to learning that 'occurs as a direct participation in the events of life' (Houle, 1980). In this case learning is facilitated by the individual. David Kolb's work on experiential learning in which learning takes place in a cyclical manner acts as a point of reference for experiential education especially in the area of higher education.

\section{Experiential Learning: a Constructivist Perspective}

The school of thought emphasizing learning through reflection on experience, considers individuals to gain and construct knowledge by interacting with their environment through a set of perceived experiences (Fenwick, 2001). Works of Kolb (1984), Piaget (1966), Dewey (1938) and Wells (1995) have greatly contributed to the constructivist view of experiential learning. The theory of constructivism implies that the learners or the individuals are constructors of their own knowledge which is generated by interacting with their socio-cultural environment (Vygotsky, 1978). Constructivists like David Kolb whose book entitled, "Experiential Learning" published in 1984, focuses more on individual development through reflection on its past experiences but issues of cognition with respect to environment interaction tend to lack from his theoretical model. Bandura (1977) emphasized that children tend to imitate adults' actions based on their perception. Learning experts must understand that the experiential diaphragm of individuals is filled with information starting from their childhood and lasts throughout life. During their life individuals tend to draw on their experiences of their interaction with people, places, situations and environments. Students 
especially when moving ahead from their adolescence towards young adulthood are prone to absorbing experiences which occur as a part of their daily life. Teachers as constructivists must be able to understand the psychological mind-sets of students and help them engage in the knowledge interpretation process by imparting a constructive approach to learning.

\section{Understanding the Modalities of the Kolbian Cycle}

Kolb's experiential learning cycle is considered to be one of the most influential theoretical models in management education illustrating the nature of experiential learning (Vince, 1998; Cunningham, 1994). Kolb's model describes learning as, "the process whereby knowledge is created through the transformation of experience" (Kolb, 1984). This model proposes six assumptions (Vince, 1998; Kayes, 2002) which are (Kolb, 1984; p.25-38):

- Learning is a process not outcome.

- Learning is driven from experience.

- Learning requires the learner to resolve conflicts through dialect.

- Learning carries a more holistic and an integrative view.

- Learning requires the individual to interact with its environment.

- Learning creates knowledge.

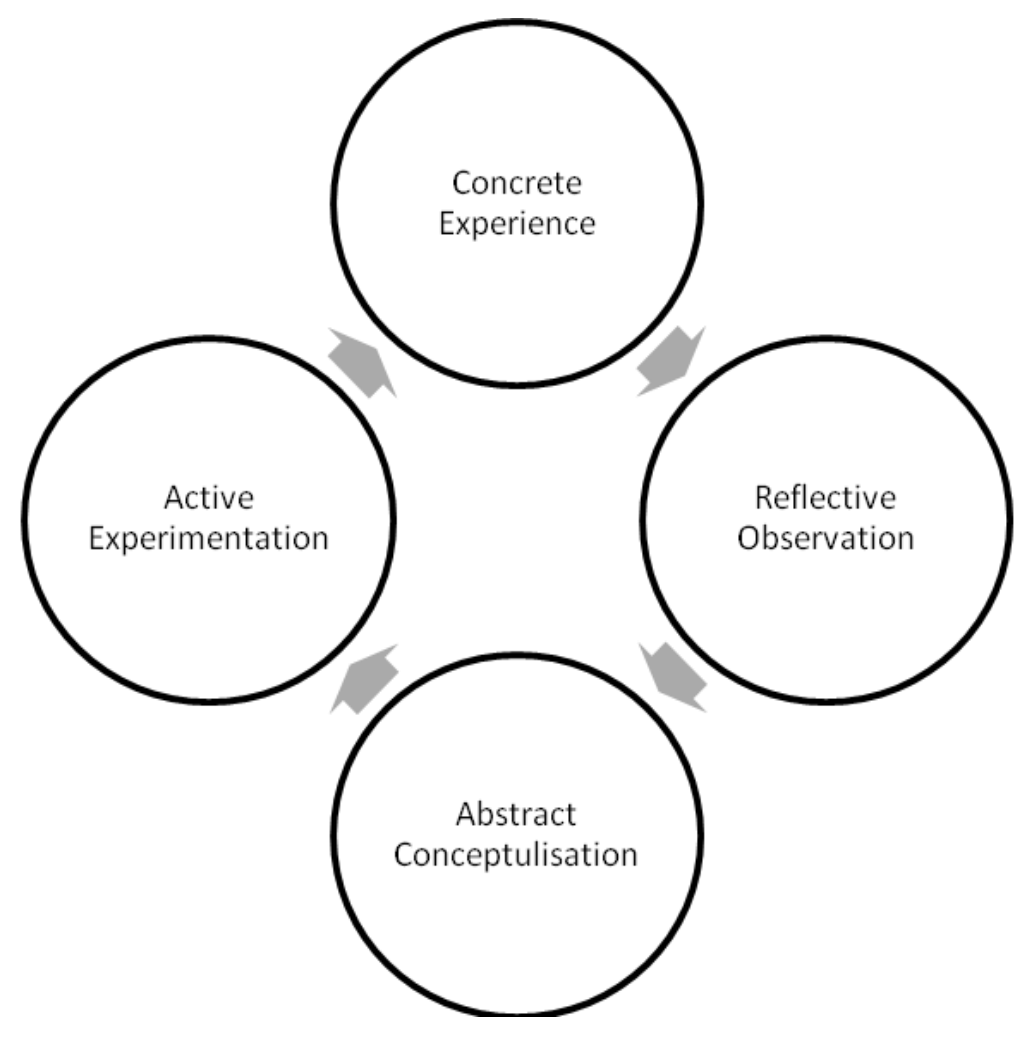

Figure 1. Kolb's (1984) Experiential Learning Cycle

Source: Kolb (1984), "Experiential Learning: Experience as the Source of Learning and Development" 
The cycle emerges from the third proposition that a learner is required to interact with the environment as an individual and resolve conflicts, whereas, this provides a link to other ideas of individual development and knowledge creation (Vince, 1998). Manager or a learner learns by responding to the set of diverse demands through two dimensions of knowledge: acquisition and transformation (Kayes, 2002). In order to learn, individuals first acquire knowledge of the complex situations or demands resulting into gaining knowledge (concrete experience) and breaking down of the knowledge into meaningful chunks (abstract conceptualization). The second dimension 'transformation' is responsible in the learning process, which helps the individual to recall or reflect upon the experience gained (reflective observation) and stimulates the learner to interact with the environment (active experimentation) (Kayes, 2002). However, when the process ends, it is again initiated through the results gained from previous active experimentation and the learner would now choose a different approach or a strategy to achieve its goal.

\section{Theoretical Discourse of Kolb's Experiential Learning Cycle}

The main theme of this section is to contradict with intent to provide an overview to assess the strengths and weaknesses of the learning cycle. The methodology for conducting the analysis is based upon a comparison of Kolb's (1984) learning cycle with a compilation of alternative conceptions to learning. Fenwick (2001) has suggested that traditional theories and practices have been unsuccessful to acknowledge the significance of "multidimensional experience" of individuals, with "overly deterministic understandings" of experience, cognition, and relationship of perception, experience, knowledge and the learning process.

In a compilation of literature, Fenwick (2001) has identified four alternate conceptions to learning. According to Fenwick (2001) these have been selected on the basis of their significance in the literature or due to their originality, which logically question the constructivist view of theorists. The four alternate conceptions are (i) the psychoanalytic (interference) perspective, (ii) the situative (participation) perspective, (iii) the critical cultural (resistance) perspective and (iv) enactivist (co-emergence) perspective. Following is a detailed discussion about each of the conceptions with respect to Kolb's learning cycle:

\subsection{The Psychoanalytic Perspective}

The psychoanalytic perspective indicates that a learner's mind is involved in a struggle between the conscious and the unconscious mind referred as to the "inner-world". However, the conscious mind is responsible for generating anxiety (force) which may result as a barrier and causes hindrance in learning and gaining knowledge (Britzman, 1998). The unconscious defense mechanism may pose a threat to learning (Hirschhorn, 1988; Vries, 1991). Anxiety might limit the learner's ability to learn, as anxiety itself is a very common emotional experience (Vince, 1998). Kolb's learning cycle has been unsuccessful to address the emotional experience of a learner at the start of the cycle, leading in two directions (i) holding anxiety (promoting learning) (Britzman, 1998; Fenwick 2001; Vince 1998) and (ii) fight or flight (discouraging learning) (Miller \& Rice 1967; Bion, 1961; Trist \& Murray, 1990; Vince, 1998)[See Appendix-I, Figure-4, Pp 15). Moreover, Kolb’s learning cycle lacks 
the inclusion of "here and now" the "immediate experience" of a learner (Vince, 1998) and focuses on the past events. The perception of a learner (as a whole) incorporates the immediate experience ("living in the moment") triggering the event and past experiences (Schein, 1993).

\subsection{The Situative Perspective}

The situative perspective proposes that learning is situated in the environment that a learner interacts with, it is not a theoretical or an intellectual concept inside a learner's head upon which it can be reflected (Fenwick, 2001). The cycle provides inadequate information about the environment of the learner, hence maintaining the status quo of resisting the influx of new information or adapting to the environment undermining the cycle's effectiveness. Beckett and Hager (2000) described experiential learning in an organizational environment to be focused on individuals "practical judgment" of the workplace context. Individuals here refer to their perception "cognitive, affective and social" (Winch, 1998). Kolb's cycle, in order to complete its revolution and again start at concrete experience requires individuals to be dependent on their eloquence, cognition and community of practice. Often, researchers have also questioned the actors in a certain environment (Ellsworth, 1997), which might act as important factors in making or streaming of an experience (good or bad) when related.

\subsection{The Critical Cultural Perspective}

The critical cultural perspective as a third alternate views power as being inseparable from experience. Furthermore, power as an influence of one's self development cannot be undermined (Fraser, 1989), whereas, Kolb's cycle has not been able to address the issues of power relations. Researchers in the field of critical cultural pedagogy propose that resistance is generated when cultural power mechanisms are formed (Gore, 1993; McLaren, 1994; Kellner, 1995). Kolb's cycle emphasizes on direct experience of the learner, but in order to include power there needs to be a transitional shift from individuality to subjectivity (Flax, 1993). The learning cycle needs to be extended from individual's learning through experience to a contemporary model that incorporates (i) "creation of knowledge" through power relations and (ii) "role of subjectivity" in creating relations (Vince, 1998). Hence, such a dimension will enhance the learner's capability to be creative, stress on relations and structure the current experiences of one's self in the society.

\subsection{The Enactivist Perspective}

The enactivist perspective relates to the concept of enacting environment and cognition simultaneously to facilitate learning (Fenwick, 2001). These are interconnections between two systems, when they coincide; it generates a response in the other system (Maturana \& Varela, 1987). In order to make an individual learn, a dialect between the individual's cognition and the environment needs to be established. Kolb's learning cycle has also not been able to relate to the interaction of cognition with the environment. Furthermore, investigation into the aforementioned perspective has shown that a dialect facilitates the learner to understand the multidimensional meanings (Individually or collectively) (Piper \& 
Thompson, 1991). This "metastructural level" provides varied meanings of individual and collective contexts (Vince, 1998). Hence the model is inadequate to help managers to understand the reflections and actions (Vince, 1998) of the interaction of cognition with environment.

\section{Reconceptualizing the Experiential Learning Model}

The theoretical discourse in the previous section has identified certain gray areas in Kolb's learning cycle based on the Poststructural analysis as alternate conceptions to learning. The authors have tried extracting the critical areas in the Kolb's learning cycle through a process of 'language-behavior' to 'textual-analysis' of critics and proponents of Kolb. The aim is to conceptualize the experiential cycle by incorporating the deficiencies through a constructivist approach. The deficiencies in the experiential learning cycle have been tabulated from alternate conceptions to future development in the cycle. The proposed tabulated piece of literature is indicated as a 'table of facts' which may be considered as an agglomeration of the literature review which focuses on the inadequacy and possible future enhancements to the learning cycle. The matrix consists of five columns and four rows. The 'table of facts' will be helpful to researchers in identifying the key areas missing and who look to address key issues and extend the model.

\begin{tabular}{|l|l|l|l|l|}
\hline S\# & $\begin{array}{l}\text { Alternate } \\
\text { Conceptions }\end{array}$ & $\begin{array}{l}\text { Deficiencies in } \\
\text { Kolb's ELC }\end{array}$ & Issues Identified & Future Development \\
\hline 1. & $\begin{array}{l}\text { Psychoanalytic } \\
\text { Perspective }-\end{array}$ & $\begin{array}{l}\text { Emotional } \\
\text { experience of the } \\
\text { learner }\end{array}$ & $\begin{array}{l}\text { Anxiety (Internal } \\
\text { Stimuli), Desire } \\
\text { (Self-motivation) }\end{array}$ & $\begin{array}{l}\text { Identifying immediate } \\
\text { experiences, } \\
\text { encourage to learn } \\
\text { and reduce anxiety }\end{array}$ \\
\hline 2. & $\begin{array}{l}\text { Situative } \\
\text { Perspective }\end{array}$ & $\begin{array}{l}\text { Participation of } \\
\text { learner in a } \\
\text { situation }\end{array}$ & $\begin{array}{l}\text { Participation, Practical } \\
\text { Judgment, Perception }\end{array}$ & $\begin{array}{l}\text { Improving perception } \\
\text { through structured } \\
\text { learning }\end{array}$ \\
\hline 3. & $\begin{array}{l}\text { Critical Cultural } \\
\text { Perspective }\end{array}$ & $\begin{array}{l}\text { Cultural aspects of } \\
\text { self-development } \\
\text { (Individually \& } \\
\text { Collectively) }\end{array}$ & $\begin{array}{l}\text { Power influence, Power } \\
\text { relations, Subjectivity, } \\
\text { Socio-political } \\
\text { perspective }\end{array}$ & $\begin{array}{l}\text { Self development } \\
\text { through power } \\
\text { relations (creation of } \\
\text { knowledge) }\end{array}$ \\
\hline 4. & $\begin{array}{l}\text { Enactivist } \\
\text { Perspective }\end{array}$ & $\begin{array}{l}\text { Simultaneous } \\
\text { Interaction of } \\
\text { cognition with } \\
\text { environment }\end{array}$ & $\begin{array}{l}\text { Dialect, Processing of } \\
\text { thoughts }\end{array}$ & $\begin{array}{l}\text { Facilitating reflection } \\
\text { of experience through } \\
\text { a process of dialect or } \\
\text { interaction }\end{array}$ \\
\hline
\end{tabular}

Table 1. Table of Facts - Self Extracted from Literature

Discourse Analysis of Kolb's Learning Cycle and Corresponding Deficiencies 
In-depth analysis into the Kolbian cycle yielded a table of facts, which reveals that the alternate conceptions of learning implicate the process of learning. The conceptions cannot be isolated from the learning process which impacts the learner, learning and its associative derivation of experience. The authors would like to propose that if these alternate conceptions are combined with a constructivist view many deficiencies of Kolb may be addressed. Furthermore, using the table of facts, the authors have proposed that the psychoanalytic and enactivist perspective depict the inner-environment of the learner while situative and cultural perspective influences the outer environment of the learner in the learning cycle. Each circle in the framework represents an environment which either impact the learner in close proximity or the learning cycle.

The psychoanalytic perspective renders itself to the relationship of the inner thought process to the outer world knowledge. This may have a considerable impact on the interpretation of experience of individuals in the cycle. The enactivist perspective indicates that the learner is in a continuous process of accepting the changes by using the power of reflection on actions and past experiences. This can affect the output of the learning experience when cognitive abilities of the learner are challenged. The situative circle denotes the level of participation and judgment that an individual encounters in a situation. The forces such as external and internal motivation may play a key role in the judgment and decision process of the learner. However, internal motivation may be subject to the psychological and physical states of the leaner. The critical cultural perspective has an influence on the learner's ability to perceive thy self and the situation based on the programmed knowledge (the knowledge gathered through values, norms, society, ethnicity etc.). These perspectives can be divided into two distinct environments based on its features to impact the learner and the learning process.

In an attempt to re-conceptualize the model, we have proposed that the two environments acting upon an individual in the learning cycle includes: a). the first environment is the internal environment (consisting of psychoanalytic forces and enactivist forces); and b). the second is the external environment (consisting of the situative forces ad critical cultural forces) exert pressure on the learning cycle. The perturbation ignites the process of learning which may also be known as reinforced learning. This type of learning may be able to address the wide range of issues lacking from the Kolb's experiential learning cycle. The aforesaid four perspectives or environments have been observed by the authors in a period of five years while teaching students and using experiential learning methodologies. The authors have somewhat able to relate the ability to think experientially by students to Carver's (1996) model of ABC's of experiential education. However, the discussion of environmental impact from within and outside the individual was given less priority in Kolb's cycle.

Transfer of knowledge has been an area of concern for learning specialists who have focused on the experiential interaction of students and teachers (Jacobs, 2003). Bates et al. (2000) suggest that structural techniques in experiential learning can be utilized as a means of enhancing transfer of knowledge into performance. In our experience as academics, the role of a teacher (facilitator) in experiential education is of great significance. Students are 
valuable but vulnerable and naïve especially when it comes to using experience as source of learning. We have observed that while teaching undergraduate and postgraduate students, they may require the support of a teacher to help extract and interpret their experiences for sharing and reflection. The teacher as a facilitator must be able to understand the physical, emotional and psychological state of students and direct their efforts accordingly (Carver, 1996). If left alone, students might wander off into imagination beyond control. Lawson et al. (1997) suggest that educational institutes are focusing more on pedagogical methods aimed at traditional lecturing techniques where experience is no more than an intrusion. Educational institutes must now understand the importance of experiential education which has evolved as a core method and an appreciative tool in the development of students in university-setups (Holton, 1996). The authors were able to predict certain experiential behavior of students based on their interaction with their psychoanalytic, situative, enactivist or cultural environment.

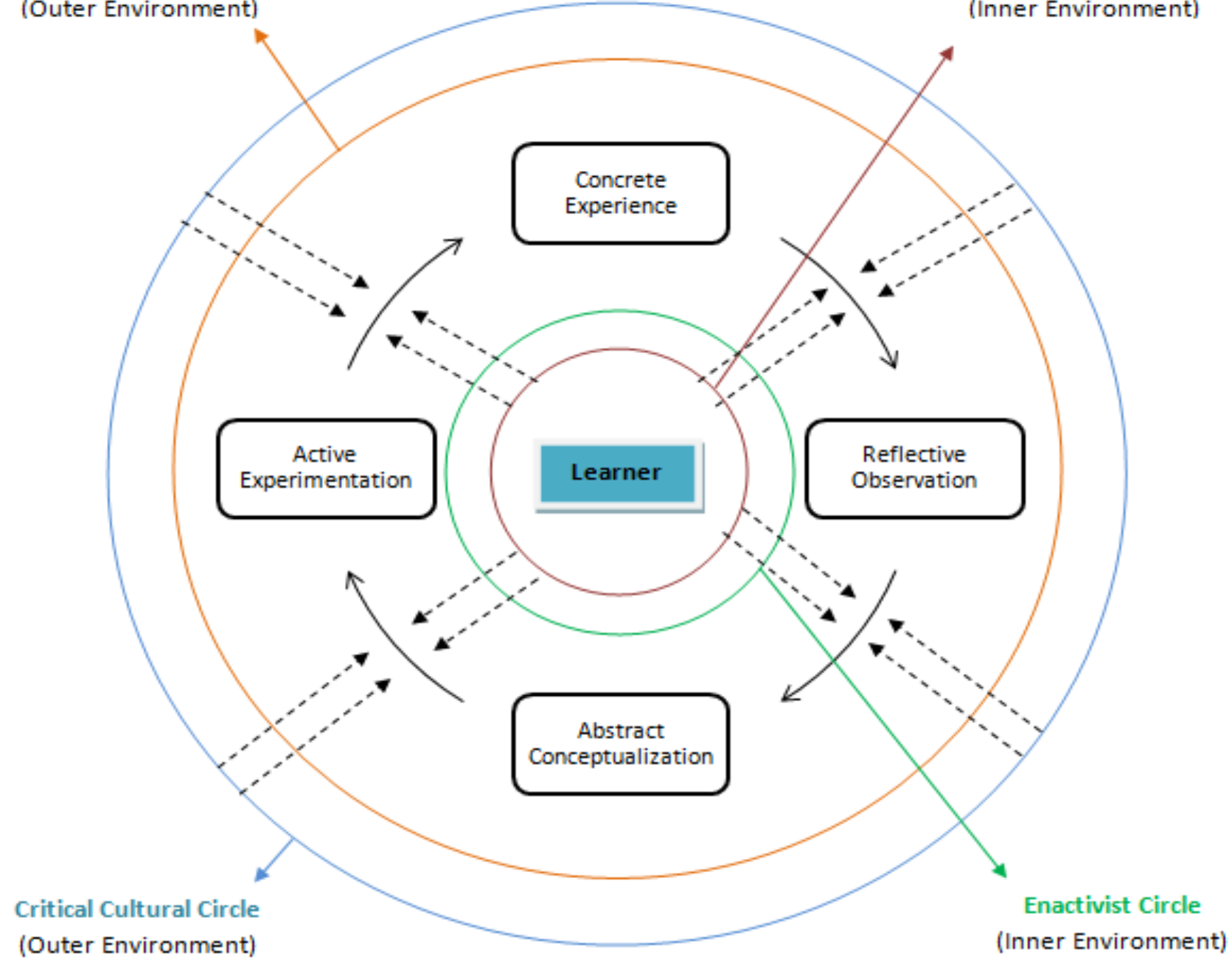

Figure 2. Reconceptualized Outlook of Kolb's Experiential Learning Cycle 


\section{Conclusion}

2011, Vol. 1, No. 2

The critical analysis of Kolb's learning cycle reveals that the constructivist view of learning which indicated creation of knowledge through experience is not only based on the learner but several other perspectives which act as forces exerting pressure on the learner. Kolb's (1984) cycle has depicted areas and concerns which Kolb wasn't even able to address properly. The critical analysis of Kolb's learning cycle also revealed that the alternate conceptions to learning proposed by Fenwick (2001) could be used as a measure to observe the deficiencies in the model. Furthermore, the conceptions which are (i) psychoanalytic, (ii) situative, (iii) critical cultural and (iv) enactivist may be divided into two environments i.e. the internal and external environment. A re-conceptualization of the model shows that these forces act upon the cycle and the individual igniting the process of learning. Thus, creating more opportunity for the learning cycle to anticipate and mimic reality through experience rather used as a cliché for learning through experience.

\section{References}

Bates, R. A., Holton, E. F. III, \& Seyler, D. L. (2000). 'The Role of Interpersonal Factors in the application of Computer-Based Training in an Industrial Setting', Human Resource Development International, (3), p. 19-42

Beckett, D., \& Hager, P. (2000). 'Making Judgments as the Basis for Workplace Learning: Towards an Epistemology of Practice', International Journal of Lifelong Education 19 (4), p.300-311

Bion, W. (1961). Experiences in Groups. London: Tavistock.

Boud, D., \& Walker, D. (1991). 'Experience and Learning: Reflection at Work'. Geelong, Victoria: Deakin University Press, (ERIC Document Reproduction Service No.384 696)

Britzman, D. P. (1998). 'Some Observations on the Working of Learning', JCT Journal of Curriculum Theorizing 14 (2) p. 53-59

Casey, D. (1993). Managing Learning in Organizations. Buckingham UK: Open University Press.

Cunningham, I. (1994). The Wisdom of Strategic Learning. London: McGraw-Hill.

de Maré, Piper, R., \& Thompson, S, (1991). Koinonia: From Hate, through Dialogue, to Culture in the Large Group, London: Karnac Books

Dewey, J. (1938). Experience and Education. New York: Collier Books

Dixon, N. M., (1999). The Organizational Learning Cycle: How We Can Learn Collectively, Second Edition, Gower Publishing 
Ellsworth, E. (1997). Teaching Positions: Difference, Pedagogy, and the Power of Address, New York: Teachers College Press

Fenwick, J. T (2001). 'Experiential Learning: A Theoretical Critique from Five Perspectives', ERIC Information Series No. 385

Flax, J. (1993). Disputed Subjects: Essays on Psychoanalysis, Politics and Philosophy, London: Routledge

Fraser, N. (1989). Unruly Practices: Power, Discourse and Gender in Contemporary Social Theory, Cambridge, MA: Polity

Gore, J. (1993). The Struggle for Pedagogies: Critical and Feminist Discourses as Regimes of Truth, New York: Routledge

Hirschhorn, L. (1988). The Workplace Within, Cambridge. MA: MIT Press

Holton, E. F., III (1996). 'The flawed four level evaluation model', Human Resource Development Quarterly 7(1), p. 5-21

Jacobs, R. L. (2003). Structured on-the-job training: Unleashing employee expertise in the workplace, Second Edition, San Francisco: Berrett-Koehler Publisher

Kayes, D. C. (2002). 'Experiential learning and its critics: Preserving the role of experience in management learning and education'. Academy of Management Learning and Education, 1(2) p. 137-149

Kellner, D. (1995). Media Culture, London: Routledge

Kets de Vries, M.F.R. (1991). Organizations on the Couch, San Francisco: Jossey-Bass

Kolb, D. A. (1984). Experiential Learning: Experiences as a source of learning and development, Englewood Cliffs, NJ: Prentice-Hall

Maturana, H. R., \& Varela, F. J. (1987). The Tree of Knowledge: The Biological Roots of Human Understanding, Boston: Shambhala

McLaren, P. (1989). Life in Schools: An Introduction to Critical Pedagogy in the Foundations of Education, New York: Longman

Michelson, E. (1996). 'Usual Suspects: Experience, Reflection and the (En)gendering of Knowledge', International Journal of Lifelong Education 15 (6) p. 438-454 
Miller, E., \& Rice, A. K. (1967). Systems of Organization, London: Tavistock

Piaget, J. (1966). The Psychology of Intelligence, Totowa, NJ: Littlefield, Adams, and Co

Schein, E. H. (1993). 'On Dialogue, Culture and Organizational Learning', Organizational Dynamics, 22(2), p. 40-51

Schön, D. A. (1983). The Reflective Practitioner, New York: Basic Books

Senge, P. M. (1990). The Fifth Discipline: The Art and Practice of the Learning Organization, London: Century Business

Swanson, R.A. \& Holton, E.F. (2009). Foundations of Human Resource Development, Second Edition, San Francisco: Berrett-Koehler

Trist, E., \& Murray, H. (1990). The Social Engagement of Social Science, (Vol. 1), London: Free Association Books

Vince, R. (1998). 'Behind and Beyond Kolb's Learning Cycle', Journal of Management Education; 22(3), ABI/INFORM Global

Vygotsky, L. S. (1978) Mind in Society: The Development of Higher Psychological Processes, Cambridge, MA: Harvard University Press

Watkins, K. E., \& Marsick, V. J. (1992). 'Towards a Theory of Informal and Incidental Learning in organizations', International Journal of Lifelong Education 11 (4), (ERIC No. EJ 451048) p. 287-300

Wells, G. (1995). 'Language and the Inquiry-oriented Curriculum', Curriculum Inquiry 25 (3), p.233-248

Winch, C. (1998). The Philosophy of Human Learning, London and New York: Routledge 